\title{
Evolutionary Game Analysis of Green Production Supervision Considering Limited Resources of the Enterprise
}

\author{
Yanhong Ma, Zhiyong Wan, Chunhua Jin* \\ School of Economics and Management, Beijing Information Science and Technology University, \\ Beijing, China, 100192
}

Received: 10 June 2020

Accepted: 6 September 2020

\begin{abstract}
Environmental issues recently have emerged as an important research problem. The enterprise's green production and the government's supervision is the keyway to reduce environmental hazards. Against this background, in this paper, we described green production supervision as a game between the enterprise and the government. Unlike previous studies, we considered the impact of limited resources of the enterprise when building the game model, which makes the model more in line with the actual situation. Because of the bounded rationality of the players, an evolutionary game model is built. The enterprise's goal was profit maximization in the game. And the government's goal was assumed to be social profit maximization. Solving the evolutionary game model, the evolutionarily stable strategy (ESS) of the model is obtained. Then, an impact analysis of how supervisory parameters affected the ESS is provided. Subsequently, we proposed some effective measures to reduce environmental hazards, such as increasing the penalty on the enterprise once pollution is discovered, reducing the mandatory green production cost reasonably, increasing the taxation ratio and improving public participation. The specific conditions of these parameters for better ESS are given based on the impact analysis. These conditions can guide the government's decision-making in green production supervision.
\end{abstract}

Keywords: green production, limited resources, government supervision, evolutionary game, policy suggestion

\section{Introduction}

China's economic development has entered into a "new normal," and as a result, environmental issues have become one of the nation's key concerns. One of

*e-mail: bimjch@126.com
China's current strategies is to explore a new and highquality development path that is oriented by ecological priority and green production [1]. This holds true for global development. Under the influence of multiple complex factors, however, large amounts of pollutants are released into the environment every year-including, for example, the occurrence of random environmental accidents [2], the dispersion of the location of occurrence, the profit maximization of the enterprise, 
and the imperfection of government regulation [3, 4]. Against this background, how to reduce environmental pollutant emissions has become a fundamentally important research topic in the field of environmental safety management.

To realize green development, the enterprises that produce harmful substances that pollute the environment during production are required to install pollution control equipment. This equipment usually is costly. Because of limited resources, the enterprise may not install the pollution control equipment voluntarily. Consequently, the government has to take supervisory measures to inspect the enterprise's green production. If a government has discovered the illegal behavior of an enterprise, it is responsible for cleanup and penalty costs. In China, the local government usually is responsible for green production supervision because the enterprise's income contributes to the performance of these local governments. Also, local government's supervision measures affect the enterprise's income, which demonstrates that a strategic interaction in fact exists between the government and the enterprise.

The traditional game model has been used to analyze this strategic interaction between the government and the enterprise in the evaluation of supervision problems. The government and the enterprise can reach an equilibrium by balancing costs and benefits [5]. A multistage game model also has been proposed to analyze the strategic interaction among the government, the manufacture, and the energy supplier in a residential energy-efficiency program. The impact of rebound, consumer behavior, and government policies (tax policies and subsidy) have been considered using the game model [6]. Similarly, Ma et al. has studied how subsidy affects the game between the enterprise and the government [7]. The impact of some other factors, such as a cooperative contract between the manufacture and the retailer [7, 8], and the social welfare of an enterprise's green production decision, also have been analyzed [9].

Because of the bounded rationality of the players and the dynamic characteristics of the game [10], the evolutionary game has been proposed and used to analyze strategic interactions between the government and the enterprise in government supervision problems. Extensive researches have investigated China's coal mine safety inspection system by using an evolutionary game $[11,12,13]$. Specific to green production supervision problems, the impact of various carbon taxes and subsidies on the enterprise's lowcarbon production methods was analyzed by using the evolutionary game model $[14,15]$. Jiang et al. considered the multiagent environmental regulation problem under Chinese fiscal decentralization [16]. In their study, they used evolutionary game theory to unpack the interactive strategies of the polluting enterprise, local government regulators, and central government planners. Cui et al. studied the green agriculture game through building an evolutionary game between the government and the farmer [17].

These researches have shown that the impact of many external influencing factors on the game between the government and the polluting enterprise have been studied extensively. The external influencing factors include government subsidies, tax policies, consumer behavior, public participation. In addition to these external factors, the enterprise imposes many internal factors as well. The enterprise's goal is profit maximization. As pollution control equipment demands a large amount of resources and the total resources of the enterprise are limited, the impact of the equipment cost on production yield becomes an important factor.

Against this background, in this paper, we studied the green production supervision problem with consideration for the limited resources of the enterprise. In light of the bounded rationality of the players, we used evolutionary game theory to build the supervision game model.

This paper is organized as follows. Section 2 provides the problem description, assumptions, and notations of this paper. Section 3 builds the evolutionary game model of the green production supervision problem. Section 4 provides the analysis of the evolutionary stable strategies of the game. Section 5 gives the impact analysis of some of the parameters for the evolutionary stable strategies of the game. Last, conclusions are presented in Section 6.

\section{Model}

\section{Problem Description, Assumptions and Notations}

The players in a green production supervision game include the manufacturing enterprise and the government regulator. Normally, the government requires the enterprise to install pollution control equipment. The cost of this equipment is called the green production input cost of the enterprise. This required pollution control equipment may not be installed by the enterprise, however, because of limited resources and the opportunity benefit realized by not installing the equipment. Under this circumstance, the government takes supervisory measures to ensure compliance of the enterprise's green production.

In the game between the government and the enterprise, the enterprise chooses whether to implement green production. Therefore, the strategy space of the enterprise is defined as $T_{c}=\{$ Green, Not Green $\}$. Assume the total resources of the enterprise are $R$, which can generate profit $I$. The green production input cost is $S_{c}$, which can generate profit $S_{c}^{h}$ if it is put into production; $h$ denotes the output coefficient and $h>0$. If the enterprise implements green production, then its production profit is $I-S_{c}^{h}$. And if the enterprise does not implement green production, its production profit is $I$ because all the resources are invested into production. 


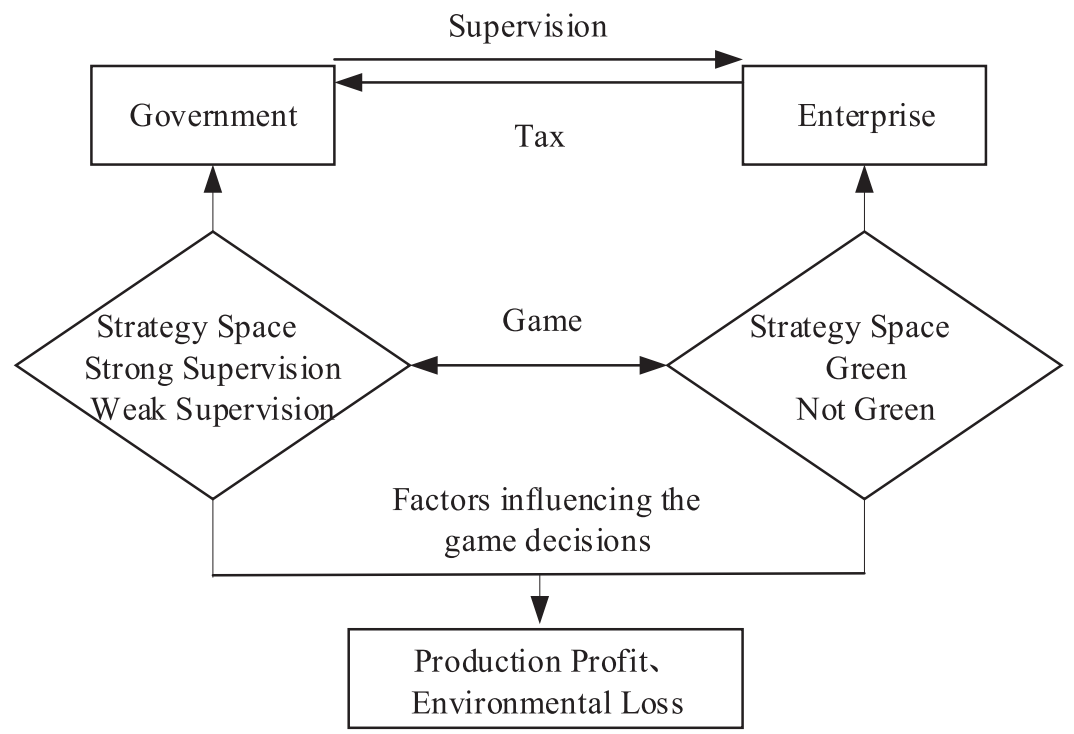

Fig. 1. The relationship between the enterprise's green production decision and the government's supervision decision.

In addition, the government chooses whether to supervise the enterprise strictly. The strategy space of the government is defined as $T_{g}=\{$ Strong Supervision, Weak Supervision\}. The cost of strong supervision is $S_{g}$. The cost of weak supervision is assumed to be 0 in this paper.

The relationship between the government's decision and the enterprise's decision is shown in Fig. 1.

Fig. 1 illustrates the static game relation between the government and the enterprise. In the traditional game model, players are assumed to be perfectly rational. In reality, however, because of incomplete information, limited cognitive ability of the decision-makers, and the decision-making environment, players are always bounded rational. A bounded rational enterprise may not choose the optimal decision after one game. Instead, it may adjust its decision gradually, according to the experience of many games with the goal of maximizing its own benefits. The government adjusts its decision in the same way during the game. Finally, the two players will reach a relatively stable state. Against this background, we introduced evolutionary game theory to analyze the dynamic evolutionary characteristics of the green production supervision game between the government and the enterprise in this paper.

Before building the game model, the assumptions of this paper are given, as follows:

Assumption 1: Environmental pollution happens only when the enterprise's decision is not green, and the government's decision is weak supervision.

Because the location of environmental pollution is relatively scattered, the pollution may not be discovered by the government or the public. Consequently, we have assumption 2.

Assumption 2: Environmental pollution is discovered with probability $P$.

It is obvious that the enterprise seeks to maximize its own profit. Then the assumption is as follows:
Assumption 3: The goal of the enterprise is profit maximization.

During the game, the government should consider production profit, environmental hazards to the society, and other losses or gains brought by its strategy. Therefore, its goal is to realize global optimum in social terms.

Assumption 3: The goal of the government is social profit maximization.

The notations of the variables and the parameters used in this study are as follows:

$S_{c}$ : The cost of green production of the enterprise.

$S_{g}$ : The cost of strong supervision of the government.

$P$ : The probability that pollution is discovered.

$\tau$ : Taxation ratio.

$r_{c}$ : The reward the enterprise gets from the government when it implements green production and the government's decision is strong supervision. Normally, this reward means receiving some policy support.

$F_{0}$ : The penalty the enterprise gets from the government when it does not implement green production and the government's decision is strong supervision. This penalty is denoted by a fine.

$F_{c}$ : The penalty the strategy combination is not green, weak supervision $\}$ and the pollution is discovered by the public. This penalty is also denoted by a fine.

$r_{g}$ : The gain or loss of the government's credibility. If the strategy combination is not green, strong supervision\}, the government credibility will be enhanced. Conversely, if the strategy combination is \{not green, weak supervision\} and the pollution is discovered by the public, the social credibility will decline.

$h$ : The output coefficient of the enterprise's production.

I: The profit when all resources are put into production. 
$L_{c}$ : The cost of pollution treatment of the government once the pollution is discovered by the public.

$E$ : The environmental hazards to the society when the strategy combination is not green, weak supervision\}.

\section{Payoff Matrix Analysis of Stage Game}

In each stage game, we assumed players to move simultaneously. If the government's decision was strong supervision and the enterprise's decision was green production, the enterprise's payoff would be, $(1-\tau)\left(I-S_{c}^{h}\right)+r$ and the government's payoff would be $I-S_{c}^{h}-S_{g}$. If the government's decision was weak supervision and the enterprise's decision was green production, the enterprise's payoff would be $(1-\tau)\left(I-S_{c}^{h}\right)$, the government's payoff would be $I-S_{c}^{h}$. If the enterprise's decision was not green, once the government inspected the enterprise, it had to install the pollution control equipment immediately. Also, it had to undertake the penalty imposed by the government. Under this circumstance, the enterprise's payoff would be $(1-\tau)\left(I-S_{c}^{h}\right)-F_{0}$ and the government's payoff would be $I-S_{c}^{h}-S_{g}+r_{g}$. If the government did not adopt strict supervision measures when the enterprise did not install pollution control equipment, then there would be environmental hazards $E$. The environmental hazards were discovered by the public with probability $P$. Once discovered, the enterprise had to eliminate the pollution with $\cos t L_{c}$. The penalty $F_{c}$ also existed under this condition. Then the enterprise's payoff would be $(1-\tau) I-P\left(L_{c}+F_{c}\right)$. Correspondingly, the government's payoff would be $\left.I-(1-P) E-P L_{c}-P r_{g}\right)$. Therefore, the stage game of green production supervision can be given as shown in Table 1.

\section{Evolutionary Game Model of Green Production Supervision}

Because of the bounded rationality, the players adjusted their decisions gradually according to the results of each stage game. Then, we built the evolutionary game model of green production supervision based on the payoff matrix analysis of stage game. Suppose the players were drawn randomly in pairs from two populations and received the expected payoffs noted in Table 1. For the government's utility, $y$ represents the probability when it takes the pure strategy "Strong Supervision" and $x$ represents the current proportion of the population of the enterprise taking the pure strategy "Green." Then the expected payoffs of the enterprise and the government are denoted as shown in equation (1) and equation (2), respectively:

$$
\begin{gathered}
u_{c}(x, y)=(x, 1-x) A\left(\begin{array}{c}
y \\
1-y
\end{array}\right) \\
u_{g}(x, y)=(y, 1-y) B^{T}\left(\begin{array}{c}
x \\
1-x
\end{array}\right)
\end{gathered}
$$

...where

$A=\left(\begin{array}{ll}(1-\tau)\left(I-S_{c}^{h}\right)+r_{c} & (1-\tau)\left(I-S_{c}^{h}\right) \\ (1-\tau)\left(I-S_{c}{ }^{h}\right)-r_{c} & (1-\tau) I-P\left(L_{c}+F_{c}\right)\end{array}\right)$,

and

$B=\left(\begin{array}{ll}I-S_{c}{ }^{h}-S_{g} & I-S_{c}{ }^{h} \\ I-S_{c}{ }^{h}-S_{g}+r_{g} & I-(1-P) E-P L_{c}-P r_{g}\end{array}\right)$

Then, the standard two-population replicator dynamics model of the green production supervision game can be written as follows:

$$
f(x)=\frac{d x}{d t}=x(1-x)\left\{y\left[(1-\tau) S_{c}{ }^{h}+2 r_{c}-P L_{c}-P F_{c}\right]-\left[(1-\tau) S_{c}{ }^{h}-P L_{c}-P F_{c}\right\}\right.
$$

$$
\begin{aligned}
g(y)=\frac{d y}{d t} & =y(1-y)\left\{x\left[S_{c}^{h}-(1-P) E-P L_{c}-P r_{g}-r_{g}\right] .\right. \\
- & {\left.\left[S_{c}^{h}-(1-P) E+S_{g}-P L_{c}-P r_{g}-r_{g}\right]\right\} }
\end{aligned}
$$

Table 1. Stage game of green production supervision.

\begin{tabular}{|c|c|c|}
\hline \multirow{2}{*}{ Enterprise } & \multicolumn{2}{|c|}{ Government } \\
\hline \multirow{2}{*}{ Green } & Strong Supervision & Weak Supervision \\
\hline \multirow{2}{*}{ Not Green } & $(1-\tau)\left(I-S_{c}{ }^{h}\right)+r_{c}$ & $(1-\tau)\left(I-S_{c}{ }^{h}\right)$ \\
\cline { 2 - 3 } & $I-S_{c}^{h}-S_{g}$ & $I-S_{c}{ }^{2}$ \\
\hline \multirow{2}{*}{ Noy } & $(1-\tau)\left(I-S_{c}{ }^{h}\right)-F_{0}$ & $(1-\tau) I-P\left(L_{c}+F_{c}\right)$ \\
\cline { 2 - 3 } & $I-S_{c}{ }^{2}-S_{g}+r_{g}$ & $I-(1-P) E-P L_{c}-P r_{g}$ \\
\hline
\end{tabular}

Note: In each payoff unit, the upper expression indicates the enterprise's payoff; the underneath expression indicates the government's payoff. 


\section{Results and Discussion}

Evolutionary Stable Strategy of the Green Production Supervision Game

Solving $\left\{\begin{array}{l}\frac{d x}{d t}=0 \\ \frac{d y}{d t}=0\end{array}\right.$, we obtained five local equilibriums of the two-population replicator dynamics model, which were as follows: $(0,0),(0,1),(1,0),(1,1)$, and $\left(x^{*}, y^{*}\right)$.

$$
\begin{gathered}
x^{*}=\frac{(1-P) E+P L_{c}+P r_{g}+r_{g}-S_{c}^{h}-S_{g}}{(1-P) E+P L_{c}+P r_{g}+r_{g}-S_{c}^{h}}, \\
y^{*}=\frac{(1-\tau) S_{c}{ }^{h}-P\left(L_{c}+F_{c}\right)}{(1-\tau) S_{c}^{h}+2 r_{c}-P\left(L_{c}+F_{c}\right)}
\end{gathered}
$$

These five local equilibriums may not be the evolutionarily stable strategy (ESS) of the replicator dynamics system. According to the method proposed by Friedman (1998), analyzing the Jacobian matrix of the differential equation can allow you to judge whether a local equilibrium is an ESS. The Jacobian matrix of a differential equation $J$ is as follows:

$$
J=\left[\begin{array}{cc}
\frac{\partial g(x)}{\partial x} & \frac{\partial g(x)}{\partial y} \\
\frac{\partial g(y)}{\partial x} & \frac{\partial g(y)}{\partial y}
\end{array}\right]=\left(\begin{array}{ll}
a_{11} & a_{12} \\
a_{21} & a_{22}
\end{array}\right)
$$

If the local equilibrium satisfies the following two conditions, then it is the ESS of the system.

Condition (1): $\operatorname{det} J=\left|\begin{array}{ll}a_{11} & a_{12} \\ a_{21} & a_{22}\end{array}\right|=a_{11} a_{22}-a_{12} a_{21}>0$,

and

Condition (2): $\operatorname{tr} J=a_{11}+a_{22}<0$. where:

$$
\begin{aligned}
& a_{11}=(1-2 x)\left\{y\left[(1-\tau) S_{c}{ }^{h}+2 r_{c}-P\left(L_{c}+F_{c}\right)\right]\right. \\
& \left.+P\left(L_{c}+F_{c}\right)-(1-\tau) S_{c}{ }^{h}\right\} \\
& a_{12}=x(1-x)\left[(1-\tau) S_{c}{ }^{h}+2 r_{c}-P\left(L_{c}+F_{c}\right)\right] \\
& a_{21}=y(1-y)\left[S_{c}{ }^{h}-(1-P) E-P L_{c}-P r_{g}-r_{g}\right], \text { and } \\
& a_{22}=(1-2 y)\left\{x\left[S_{c}{ }^{h}-(1-P) E-P L_{c}-P r_{g}-r_{g}\right)\right] \\
& \left.-\left[S_{c}^{h}-(1-P) E+S_{g}-P L_{c}-P r_{g}-r_{g}\right]\right\}
\end{aligned}
$$

In the problem of green production supervision game, the values of $a_{11}, a_{12}, a_{21}$, and $a_{22}$ in each local equilibrium are given in Table 2 .

In Table 2,

$$
\begin{aligned}
& A=x^{*}\left(1-x^{*}\right)\left[(1-\tau) S_{c}^{h}+2 r_{c}-P L_{c}-P F_{c}\right], \\
& B=y^{*}\left(1-y^{*}\right)\left[S_{c}^{h}-(1-P) E-P L_{c}-P r_{g}-r_{g}\right]
\end{aligned}
$$

In this paper, we assumed environmental pollution occurred only when an enterprise's decision was not green, and the government's decision was weak supervision. Under the other conditions, the enterprises all installed pollution control equipment voluntarily or were forced. Before analyzing the ESS of the system, we proposed the following definition of "failed supervision."

Definition 1: The condition that the enterprise's decision is not green, and the government's decision is weak supervision is defined as failed supervision.

According to the definition of failed supervision, it was evident that the probability of failed supervision was $P_{F}=(1-x)(1-y)$. Once the system obtained the ESS, the probability of failed supervision also tended to stabilize.

According to Table 2, the ESS of the green production supervision game model proposed in this paper is shown in Proposition 1.

Proposition 1:

$$
\text { case (a): If } F_{c}<\frac{(1-\tau) S_{c}^{h}}{P}-L_{c} \text { and } S_{g}>(1-P) E
$$

$+P L_{c}+(1+P) r_{g}-S_{c}^{h}$, the ESS of the system is $(0,0)$.

Table 2. The values of $a_{11}, a_{12}, a_{21}$, and $a_{22}$ in each local equilibrium.

\begin{tabular}{|c|c|c|c|c|}
\hline Local equilibrium & $a_{11}$ & $a_{12}$ & $a_{21}$ & $a_{22}$ \\
\hline$(0,0)$ & $-(1-\tau) S_{c}^{h}+P\left(L_{c}-F_{c}\right)$ & 0 & 0 & $-S_{c}^{h}-S_{g}+(1-P) E+P L_{c}+(1+P) r_{g}$ \\
\hline$(0,1)$ & $2 r_{c}$ & 0 & 0 & $S_{c}^{h}+S_{g}-(1-P) E-P L_{c}-(1+P) r_{g}$ \\
\hline$(1,0)$ & $(1-\tau) S_{c}^{h}-P\left(L_{c}+F_{c}\right)$ & 0 & 0 & $-S_{g}$ \\
\hline$(1,1)$ & $-2 r_{c}$ & 0 & 0 & $S_{g}$ \\
\hline$\left(x^{*}, y^{*}\right)$ & 0 & $A$ & $B$ & 0 \\
\hline
\end{tabular}


case (b): If $F_{c}<\frac{(1-\tau) S_{c}^{h}}{P}-L_{c}$ and $S_{g}<(1-P) E$ $+P L_{c}+(1+P) r_{g}-S_{c}^{h}$, the system is in periodical fluctuations.

case (c): If $F_{c}>\frac{(1-\tau) S_{c}^{h}}{P}-L_{c}$ and $S_{g}<(1-P) E$ $+P L_{c}+(1+P) r_{g}-S_{c}^{h}$, the ESS of the system is $(1,0)$.

case (d): If $F_{c}>\frac{(1-\tau) S_{c}{ }^{h}}{P}-L_{c}$ and $S_{g}>(1-P) E$ $+P L_{c}+(1+P) r_{g}-S_{c}^{h}$, the ESS of the system is $(1,0)$.

To better understand the trends of evolution, a simulation analysis is shown in Fig. 2. We set the baseline values of the parameters as $\tau=0.2, h=1$, $S_{c}=5, P=0.3, L_{c}=7, E=5, r_{g}=2$, and $r_{c}=2$. We set $F_{c}$, $S_{g}^{c}$ according to the four cases provided in Proposition 1 .

Proposition 1 and Fig. 1 show the ESS of the green production supervision game. Under the condition of case (a), the ESS was $(0,0)$. The ESS was $(1,0)$ under the condition of case (c) and case (d). Under the condition of case (b), the replication dynamic system showed a fluctuating trend. This meant that the system had a stable limit cycle, but it was not asymptotically stable (Liu et al., 2015). From the point of the stable state of failed supervision probability, it was 1 under case (1) and 0 under case (c) and case (d). Under case (b), the probability of failed supervision fluctuated because the system fluctuated. We assumed that the environmental hazards happened only when they experienced failed supervision. Hence, reducing the probability of failed supervision was key to reducing environmental hazards. Against this background, the ESS of case (c) and case (d) was better than that of case (b). The ESS of case (b) was better than that of case (a).

The probability of failed supervision was not 0 under the condition of case (a) and case (b), which meant that the environmental hazards may have happened under these conditions. To reduce environmental hazards, it was important to impel the system to transfer from case (a) and case (b) to case (c) or case (d). The impact of the analysis of some of the parameters on the ESS is explained in Section 5. On the basis of the impact analysis, we proposed corresponding supervision policy suggestions for the government with the goal of improving environmental quality.

\section{Discussion: The Impact Analysis of Supervisory Parameters on the ESS}

\section{The Impact Analysis of Penalty $F_{c}$}

According to Proposition 1, if $F_{c}>\frac{(1-\tau) S_{c}{ }^{h}}{P}-L_{c}$, then the ESS of the system would be $(1,0)$ and the failed supervision probability would be 0 . Otherwise, it would be possible for the environmental hazard to occur. From this point of view, increasing the penalty on the enterprise when environmental hazards are discovered under certain conditions (which is $F_{c}>\frac{(1-\tau) S_{c}{ }^{h}}{P}-L_{c}$ ) would reduce the failed supervision probability.
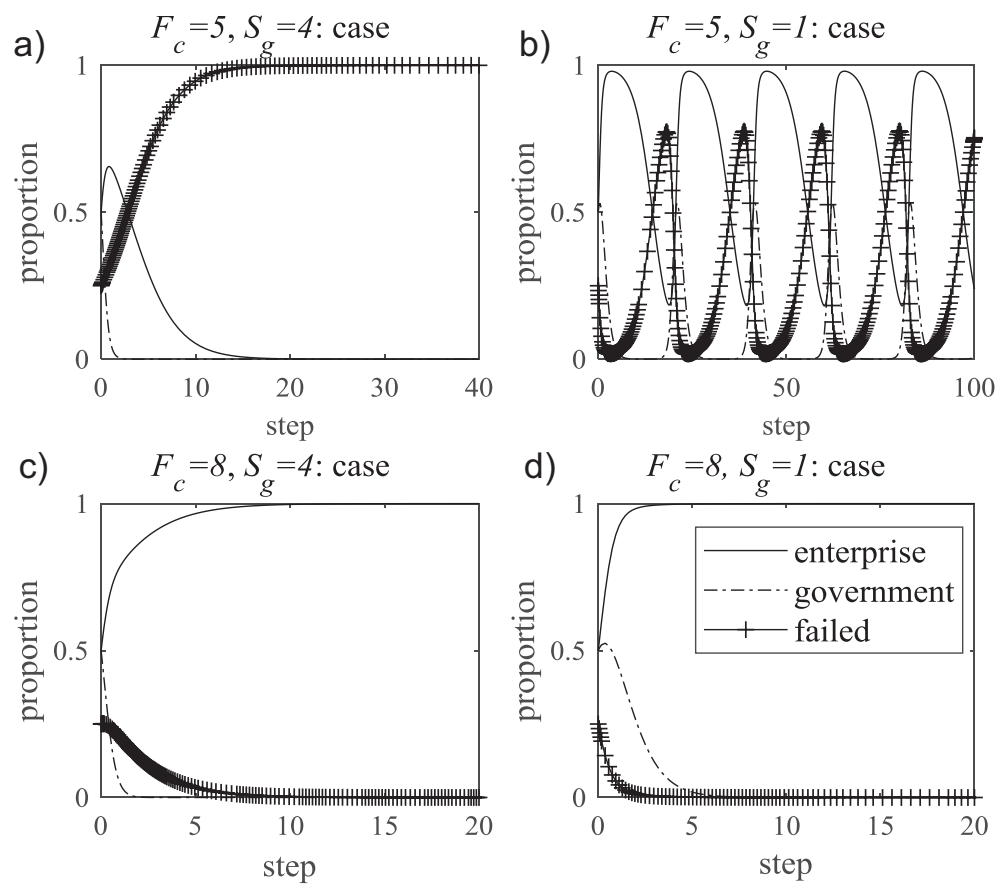

Fig. 2. The evolutionary trend of the green production supervision game. 
The transformation shown in Fig. 2 from panel (a) to panel (c) and as well as the change from panel (b) to panel (d) verify this finding.

Although increasing the penalty $F_{c}$ would reduce the probability of failed supervision, higher was not necessarily better. As long as the condition of $F_{c}>\frac{(1-\tau) S_{c}{ }^{h}}{P}-L_{c}$ was met, the ESS would be $(1,0)$.

An additional increase of $F_{c}$ only decreased the enterprise's profit without receipt of any benefits.

In a word, increasing the penalty on the enterprise when environmental hazards are discovered until it

satisfies

$$
F_{c}>\frac{(1-\tau) S_{c}{ }^{h}}{P}-L_{c} \text { can help reduce }
$$

environmental hazards. This finding can guide the govenrment to set the penalty parameter reasonably.

\section{The Impact Analysis of Green Production Cost $S_{c}$}

$S_{c}$ denotes the cost of green production of the enterprise. The higher the cost, the less willing the enterprise was to implement green production. Proposition 1 clearly stated the green production probability of an enterprise under different conditions.

If $S_{c}^{h}>\max \left\{\frac{P\left(F_{c}+L_{c}\right)}{1-\tau},(1-P) E+P L_{c}+(1+P) r_{g}-S_{g}\right\}$, then the ESS of the green production supervision game wystem would be $(0,0)$. If $\frac{P\left(F_{c}+L_{c}\right)}{1-\tau}<S_{c}^{h}<(1-P) E+P L_{c}+(1+P) r_{g}-S_{g}, \quad$ the system showed a fluctuating trend. If $S_{c}^{h}<\frac{P\left(F_{c}+L_{c}\right)}{1-\tau}$, then the ESS would be $(1,0)$. The impact of $S_{c}$ on the system is shown in Fig. 3. Because of the ESS of case (c) and case (d) are the same, we considered only case (c) in the following analysis.
Normally, the enterprise was required to install some equipment to control the discharge of pollutants. Because of limited resources, green production costs had a negative effect on enterprise profit. This contributed to the probability that green production was not 1. The impact of $S_{c}$ on the system showed that a reduction in the cost of an enterprise's green production helped to achieve an ESS of $(1,0)$. Under the premise of meeting the basic pollution control requirement, if the government reduced the mandatory green production cost according to given conditions, the enterprise would be more likely to implement green production. Then the probability of failed supervision was reduced as well as the environmental hazards.

\section{The Impact Analysis of Taxation Ratio $\tau$}

Based on Proposition 1, we obtained the following:

(1) When $S_{g}>(1-P) E+P L_{c}+(1+P) r_{g}-S_{c}^{h}$ : if $\tau<1-\frac{P\left(F_{c}+L_{c}\right)}{S_{c}^{h}}$, the ESS of the system was $(0,0)$; if $\tau>1-\frac{P\left(F_{c}+L_{c}\right)}{S_{c}^{h}}$, the ESS of the system was $(1,0)$.

(2) When $S_{g}>(1-P) E+P L_{c}+(1+P) r_{g}-S_{c}^{h}$ : if $\tau<1-\frac{P\left(F_{c}+L_{c}\right)}{S_{c}^{h}}$, the system showed a fluctuating trend; if $\tau>1-\frac{P\left(F_{c}+L_{c}\right)}{S_{c}^{h}}$, the ESS of the system was
$(1,0)$.

Consequently, in general, improving the taxation ratio was an effective measure to promote the enterprise to adopt a green production strategy. Therefore, the government could reduce the probability of failed supervision by reasonably improving the taxation ratio. The impact of the taxation ratio on the ESS is illustrated in Fig. 4 and Fig. 5.
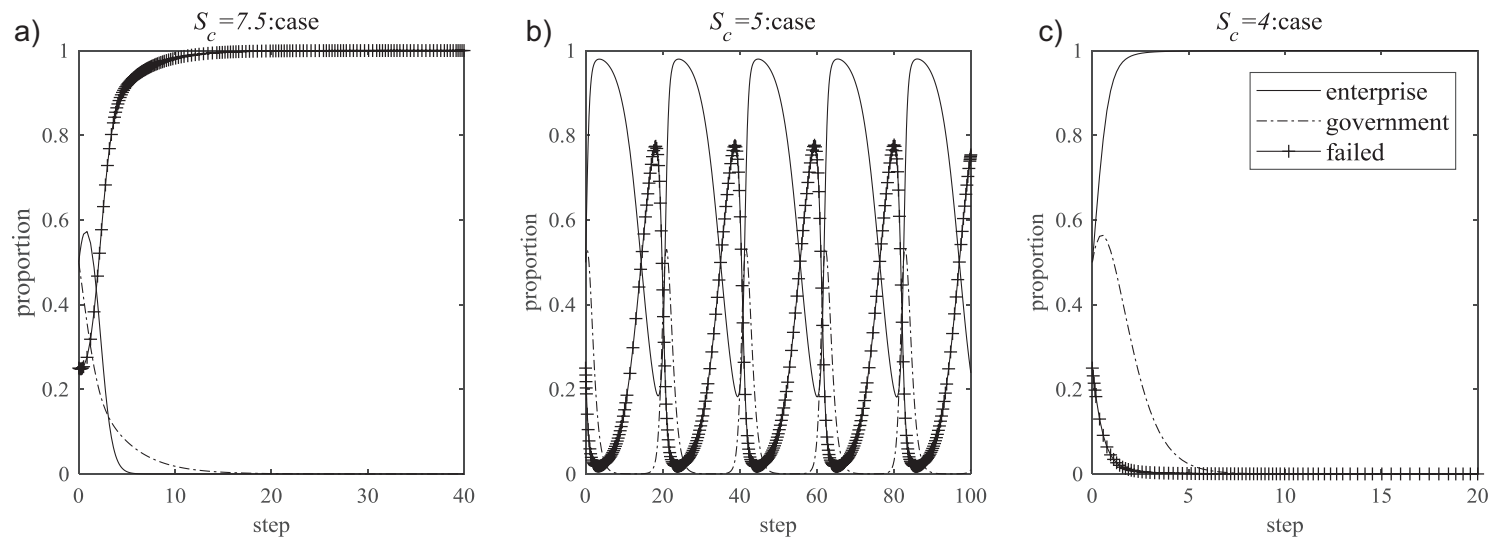

Fig. 3. The impact of $S_{c}$ on the ESS $\left(\tau=0.2, h=1, P=0.3, L_{c}=7, E=5, r_{g}=2, r_{c}=2 . F_{c}=5, S_{g}=1\right)$. 

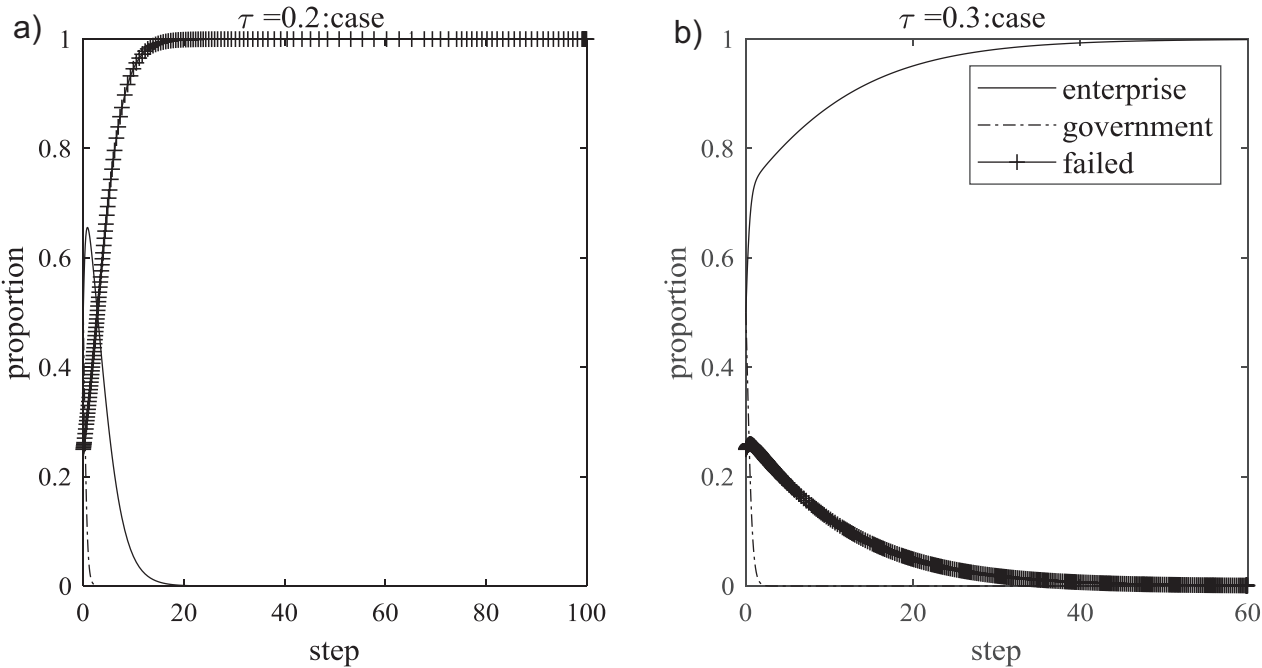

Fig. 4. The impact of $\tau$ on the ESS when $S_{g}>(1-P) E+P L_{c}+(1+P) r_{g}-S_{c}^{h}\left(h=1, P=0.3, S_{c}=5, L_{c}=7, E=5, r_{g}=2, r_{c}=2\right.$. $\left.F_{c}=5, S_{g}=1\right)$.
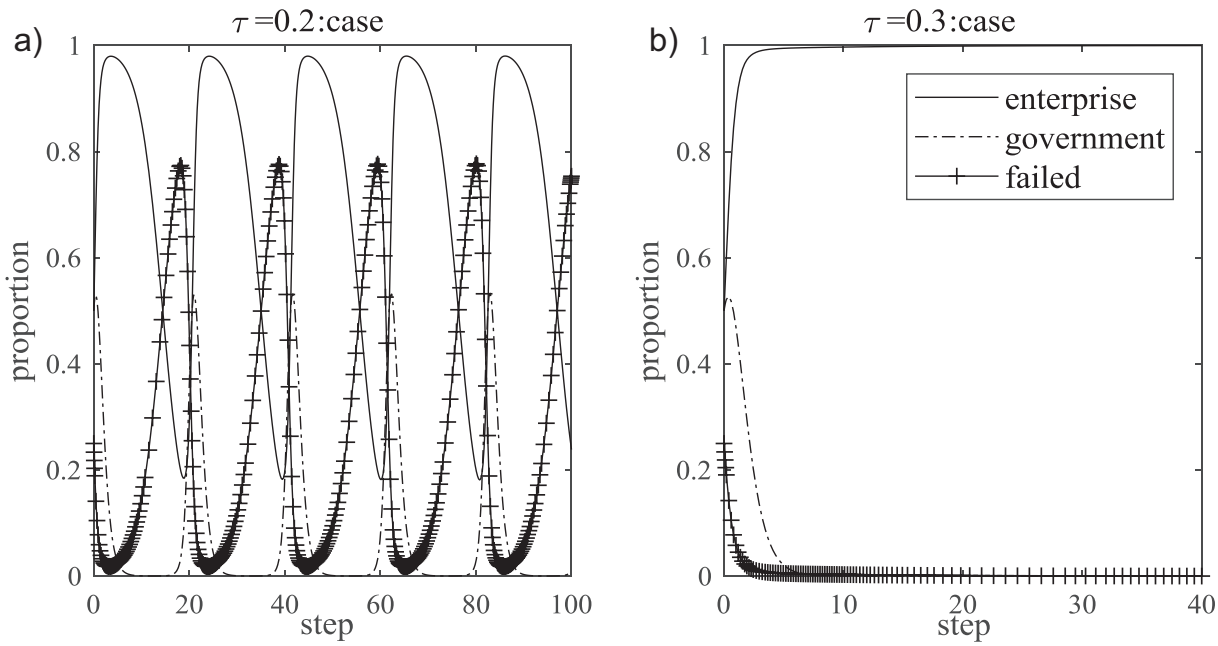

Fig. 5. The impact of $\tau$ on the ESS when $S_{g}<(1-P) E+P L_{c}+(1+P) r_{g}-S_{c}^{h}\left(h=1, P=0.3, S_{c}=5, L_{c}=7, E=5, r_{g}=2, r_{c}=2\right.$. $\left.F_{c}=5, S_{g}=1\right)$

\section{The Impact Analysis of Probability P}

Similarly, according to Proposition 1, we obtained the following:

(1) When $r_{g}+L_{c}-E>0$ : if

$P<\min \left\{\frac{(1-\tau) S_{c}^{h}}{F_{c}+L_{c}}, \frac{S_{g}-E-r_{g}+S_{c}^{h}}{r_{g}+L_{c}-E}\right\}$, the ESS of the

system was $(0,0)$; if $\frac{S_{g}-E-r_{g}+S_{c}^{h}}{r_{g}+L_{c}-E}<P<\frac{(1-\tau) S_{c}^{h}}{F_{c}+L_{c}}$, the system showed a fluctuating trend; if

$P>\frac{(1-\tau) S_{c}^{h}}{F_{c}+L_{c}}$, the ESS was $(1,0)$.
(2) When $r_{g}+L_{c}-E<0$ : if

$\frac{S_{g}-E-r_{g}+S_{c}^{h}}{r_{g}+L_{c}-E}<P<\frac{(1-\tau) S_{c}^{h}}{F_{c}+L_{c}}$, the ESS was $(0,0)$ if $P<\min \left\{\frac{(1-\tau) S_{c}^{h}}{F_{c}+L_{c}}, \frac{S_{g}-E-r_{g}+S_{c}^{h}}{r_{g}+L_{c}-E}\right\}$, the system showed a trend of fluctuations; if $P>\frac{(1-\tau) S_{c}^{h}}{F_{c}+L_{c}}$, the
ESS was $(1,0)$. $P$ means the probability that pollution was discovered. The results showed that the ESS of the green production supervision game could be transferred to a better state by improving the probability $P$. The question was how to improve the probability that pollution would be discovered. Much research has shown that building an information platform for the public and introducing 

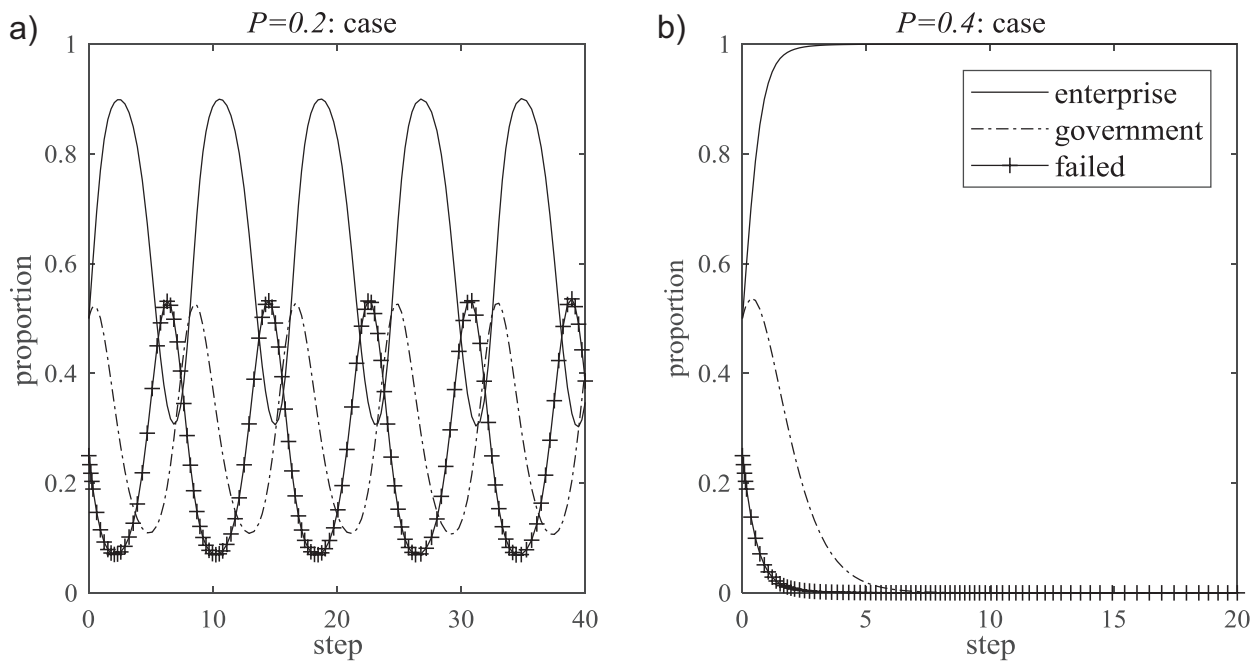

Fig. 6. The impact of $P$ on the $\operatorname{ESS}\left(\tau=0.2, h=1, S_{c}=5, L_{c}=7, E=5, r_{g}=2, r_{c}=2 . F_{c}=5, S_{g}=1\right)$.

the media to supervision are good methods to improve the probability that pollution will be discovered by the public [18-20].

Against this background, the government can improve the probability that pollution was discovered through introducing the public and the media to supervision. Then, the environmental hazard would be reduced. The impact of probability $P$ on the ESS of the green production supervision game is illustrated in Fig. 6. Only one figure is presented here, this is because the two change trends under the given conditions are the same.

\section{Conclusions}

Green production is an important development trend not only in China but also around the world. Installing pollution control equipment is one way to control the emission of pollutants and realize green production. Because of the costs associated with this pollution control equipment and the information asymmetry, the enterprise may not be willing or able to install the equipment voluntarily. Against this background, we studied the supervision game between the government's supervision strategy and the enterprise's green production strategy. Unlike previous studies, we considered the impact of the enterprise's limited resources, which was an internal factor, on the supervision game.

We built an evolutionary game model between the government and the enterprise and provided the ESS of the model. Because pollution tended to occur only when the government's decision was weak supervision and the enterprise's decision was not green, this paper analyzed the probability of this condition and defined this condition as failed supervision. Reducing the probability of failed supervision helped reduce environmental hazards. On the basis of the ESS under given conditions, we also analyzed the impact of some parameters on the ESS. The impact analysis revealed several ways to improve the ESS and to reduce the probability of failed supervision: (1) increasing the penalty on the enterprise once pollution was discovered, (2) reducing the mandatory green production cost reasonably, and (3) increasing the taxation ratio and the probability that pollution would be discovered through introducing the public and the media into supervision. This paper outlined the specific conditions of changing these parameters with the goal of reducing failed supervision probability. In general, the results of this paper provide decision-making support for the government on green production supervision, which, in turn, will help to reduce environmental hazards.

\section{Acknowledgement}

This study was supported by the Social Science Foundation of Beijing (19GLC066); the National Natural Science Foundation of China (71801137); the Development of University Connotation Scientific Research Level Promotion Project at Beijing Information Science and Technology University (2019KYNH216).

\section{Conflict of Interest}

The authors declare no conflict of interest.

\section{References}

1. WANG R. The influence of environmental regulation on the efficiency of China's regional green economy based on the GMM model. Polish Journal of Environmental Studies. 29 (3), 2395, 2020.

2. BEAVIS B., WALKER M. Random wastes, imperfect monitoring and environmental quality standards $[\mathrm{J}]$. Journal of Public Economics. 21 (3), 377, 1983. 
3. KIM S.H. Time to come clean? Disclosure and inspection policies for green production[J]. Operations Research. 63 (1), 1, 2015

4. WANG S., SUN P., de VERICOURT F. Inducing environmental disclosures: A dynamic mechanism design approach[J]. Operations Research. 64 (2), 371, 2016.

5. SCHOL J.T. Cooperative regulatory enforcement and the politics of administrative effectiveness. The American Political Science Review. 85 (1), 115, 1991.

6. SOROUSH S., MORTEZA R.B. A game theoretic approach for assessing residential energy-efficiency program considering rebound, consumer behavior, and government policies. Applied Energy. 233-234, 44, 2019.

7. MA W., ZHANG R., CHAI S. What drives green innovation? A game theoretic analysis of government subsidy and cooperation contract. Sustainability. 11, 5584, 2019.

8. JEONG E.B., PARK G.W., YOO S.H. Incentive mechanism for sustainable improvement in a supply chain. Sustainability. 11, 3508, 2019.

9. ZHANG Z., WANG Y., MENG Q., LUAN X. Impacts of green production decision on social welfare. Sustainability. 11, 453, 2019.

10. FRIEDMAN D. On economic applications of evolutionary game theory. Journal of Evolutionary Economics. 8 (1), 15, 1998

11. LIU D., XIAO X., LI H., WANG W. Historical evolution and benefit-cost explanation of periodical fluctuation in coal mine safety supervision: An evolutionary game analysis framework. European Journal of Operational Research. 243 (3), 974, 2015.

12. LIU Q., LI X., HASSALL M. Evolutionary game analysis and stability control scenarios of coal mine safety inspection system in China based on system dynamics. Safety Science. 80, 13, 2015.
13. LIU Q., LI X., MENG X. Effectiveness research on the multi-player evolutionary game of coal-mine $T$ safety regulation in China based on system dynamics. Safety Science. 111, 224, 2019.

14. CHEN W., HU Z.H. Using evolutionary game theory to study governments and manufacturers' behavioral strategies under various carbon taxes and subsidies. Journal of Cleaner Production. 201, 123, 2018.

15. FAN R., DONG L., YANG W., SUN J. Study on the optimal supervision strategy of government low-carbon subsidy and the corresponding efficiency and stability in the small-world network context. Journal of Cleaner Production. 168, 536, 2017.

16. JIANG K., YOU D., MERRILL R., Li Z. Implementation of a multi-agent environmental regulation strategy under Chinese fiscal decentralization: An evolutionary game theoretical approach. Journal of Cleaner Production. 214, 902, 2019.

17. CUI H., ZHAO T., TAO P. Evolutionary game study on the development of green agriculture in china based on ambidexterity theory perspective. Polish Journal of Environmental Studies. 28 (3), 1093, 2019.

18. LI L., XIA X., CHEN B., SUN L. Public participation in achieving sustainable development goals in China: evidence from the practice of air pollution control. Journal of cleaner production. 201, 499, 2018.

19. TILT B. China' s air pollution crisis: science and policy perspectives. Environmental science \& policy. 92, 275, 2019.

20. TANG Z., TANG J.T. Can the media discipline Chinese firms' pollution behaviors? The mediating effects of the public and government. Journal of management. 42(6), 1700, 2016. 